\title{
Multi-scale temperature variations and their regional differences in China during the Medieval Climate Anomaly
}

\author{
HAO Zhixin ${ }^{1,2}$, WU Maowei ${ }^{1}$, LIU Yang ${ }^{1,2}$, ZHANG Xuezhen ${ }^{1,2},{ }^{*}$ ZHENG Jingyun ${ }^{1,2}$ \\ 1. Key Laboratory of Land Surface Pattern and Simulation, Institute of Geographic Sciences and Natural Re- \\ sources Research, CAS, Beijing 100101, China; \\ 2. University of Chinese Academy of Sciences, Beijing 100049, China
}

\begin{abstract}
The Medieval Climate Anomaly (MCA, AD950-1250) is the most recent warm period lasting for several hundred years and is regarded as a reference scenario when studying the impact of and adaptation to global and regional warming. In this study, we investigated the characteristics of temperature variations on decadal-centennial scales during the MCA for four regions (Northeast, Northwest, Central-east, and Tibetan Plateau) in China, based on high-resolution temperature reconstructions and related warm-cold records from historical documents. The ensemble empirical mode decomposition method is used to analyze the time series. The results showed that for China as a whole, the longest warm period during the last 2000 years occurred in the 10th-13th centuries, although there were multi-decadal cold intervals in the middle to late 12th century. However, in the beginning and ending decades, warm peaks and phases on the decadal scale of the MCA for different regions were not consistent with each other. On the inter-decadal scale, regional temperature variations were similar from 950 to 1130; moreover, their amplitudes became smaller, and the phases did not agree well from 1130 to 1250 . On the multi-decadal to centennial scale, all four regions began to warm in the early 10th century and experienced two cold intervals during the MCA. However, the Northwest and Central-east China were in step with each other while the warm periods in the Northeast China and Tibetan Plateau ended about 40-50 years earlier. On the multi-centennial scale, the mean temperature difference between the MCA and Little Ice Age was significant in Northeast and Central-east China but not in the Northwest China and Tibetan Plateau. Compared to the mean temperature of the 20th century, a comparable warmth in the MCA was found in the Central-east China, but there was a little cooling in Northeast China; meanwhile, there were significantly lower temperatures in Northwest China and Tibetan Plateau.
\end{abstract}

Keywords: China; multi-scale variations; temperature; Medieval Climate Anomaly

Received: 2019-07-08 Accepted: 2019-08-16

Foundation: National Key R\&D Program of China, No.2017YFA0603300; National Natural Science Foundation of China, No.41671036, No.41831174; The Strategic Priority Research Program of the Chinese Academy of Sciences, No.XDA19040101

Author: Hao Zhixin, Professor, specialized in climate change. E-mail: haozx@igsnrr.ac.cn

"Corresponding author: Zheng Jingyun, Professor, E-mail: zhengjy@igsnrr.ac.cn 


\section{Introduction}

The impact of climate change and adaptation has become a hot spot under the background of global warming (IPCC, 2012; 2014; Qin, 2014). The Medieval Climate Anomaly (MCA, about AD950-1250), which is the most recent warm climate period lasting several centuries, has attracted increased attention when studying the impact of and adaptation to a warming climate because it can be treated as a reference period for modern warming (Crowley and Lowery, 2000; Bradley et al., 2003; PAGES, 2009; 2014). Several international paleoclimatology symposiums on this topic have been held, and special issues were published in Climatic Change (Hughes and Diaz, 1994). Diaz et al. (2011) summarized multiple high-resolution climatic proxy records. Especially, they reconstructed temperature and drought/flood data with annual to decadal resolution and found that most areas (the middle and high latitudes of the Northern Hemisphere in particular) were warmer in the MCA than in the 15th-19th centuries; meanwhile, many areas (the middle latitudes in particular) were also drier in the MCA along with regional frequent and long-lasting severe droughts. The anomalous climate lasted till the 1400 s in some regions, which had significant impacts on societies and economies all around the world.

The climate in China has various types and large variability, which might significantly impact social and economic development. China is an ideal region to study past climate change and its impact because it has plenty of consecutive historical records and natural proxies such as tree rings, stalagmites, ice cores, and lake sediments. Historical climate change in China has always been a hot spot for Chinese and international researchers (Bradley, 1993; Steffen, 2003). Significant progress has been made, and abundant climatic proxy data acquired (Ge et al., 2014; 2016). However, although there has been a number of site-based/regional temperature reconstructions back to the MCA along with research on climate anomalies during the MCA, the understanding of the characteristics of the warm climate in China during the MCA is still limited to the country as a whole and the centennial scale (Ge et al., 2013b; 2015; 2017). The special studies on the MCA were mostly published 20 years ago, and very few studies have focused on regional variations of temperature during the MCA. In this study, we combine the recently published high-resolution temperature reconstructions of longer than 1000 years with regional warm/cold records from Chinese historical documents to investigate decadal to centennial temperature variations and their regional differences in China during the MCA. The results would help provide an anomalous climate background for the study of spatial-temporal variations of impacts on Chinese agricultural society, and provide historical reference cases for future adaptation to complicated climate change considering the different regional conditions in China.

\section{Data and methods}

\subsection{Data}

The data used in this study include five published temperature reconstruction series derived from historical documents and natural evidence, covering most of the MCA over four regions in China (Northeast, Northwest, Central-east, and Tibetan Plateau). Table 1 shows the natural evidence used, the climate indicators, spatial coverage, and time resolution for each 
series. These series reflect the characteristics of the region rather than local temperature variations because they were integrated from recently published results containing several locations and multiple proxies. Moreover, regional warm/cold records from Chinese historical documents were also used as climate evidence.

Table 1 Information for published temperature reconstruction series by historical documents and natural evidence

\begin{tabular}{|c|c|c|c|c|c|c|}
\hline Region & Proxy & $\begin{array}{l}\text { Spatial } \\
\text { coverage }\end{array}$ & Indicator & $\begin{array}{l}\text { Recon- } \\
\text { structed } \\
\text { period }\end{array}$ & $\begin{array}{l}\text { Time } \\
\text { resolution }\end{array}$ & Reference \\
\hline $\begin{array}{l}\text { Northeast } \\
\text { China }\end{array}$ & $\begin{array}{l}\text { Integrated from } 5 \text { series including } \\
\delta^{18} \mathrm{O} \text { in peat, long-chain alkenone, } \\
\text { stalagmite microlayer thickness, and } \\
\text { warm/cold records. }\end{array}$ & $\begin{array}{l}\text { About } \\
110^{\circ}-130^{\circ} \mathrm{E} \\
36^{\circ}-50^{\circ} \mathrm{N}\end{array}$ & $\begin{array}{l}\text { Annual } \\
\text { mean tem- } \\
\text { perature }\end{array}$ & $\begin{array}{l}\text { AD } \\
1-2000\end{array}$ & $10 \mathrm{yr}$ & $\begin{array}{l}\text { Ge et al., } \\
2013 \mathrm{a}\end{array}$ \\
\hline $\begin{array}{l}\text { Northwest } \\
\text { China }\end{array}$ & $\begin{array}{l}\text { Integrated from } 2 \text { series of juniper } \\
\text { tree ring width from the northern } \\
\text { slope of Qilian Mountain. }\end{array}$ & $\begin{array}{l}\text { About } \\
80^{\circ}-110^{\circ} \mathrm{E} \\
38^{\circ} \mathrm{N} \text { to the } \\
\text { north border }\end{array}$ & $\begin{array}{l}\text { Annual } \\
\text { mean tem- } \\
\text { perature }\end{array}$ & $\begin{array}{l}\text { AD } \\
850-2000\end{array}$ & $10 \mathrm{yr}$ & $\begin{array}{l}\text { Ge et al., } \\
2013 \mathrm{a}\end{array}$ \\
\hline $\begin{array}{l}\text { Central-east } \\
\text { China }\end{array}$ & $\begin{array}{l}\text { Integrated from } 11 \text { series of historical } \\
\text { warm/cold records, } 3 \text { of which started } \\
\text { from } 1380 \text { and } 8 \text { of which started } \\
\text { from } 1470 .\end{array}$ & $\begin{array}{l}\text { About } \\
105^{\circ}-122^{\circ} \mathrm{E} \\
24^{\circ}-36^{\circ} \mathrm{N}\end{array}$ & $\begin{array}{l}\text { Annual } \\
\text { mean tem- } \\
\text { perature }\end{array}$ & $\begin{array}{l}\mathrm{AD} \\
1-2000\end{array}$ & $10 \mathrm{yr}$ & $\begin{array}{l}\text { Ge et al., } \\
2013 \mathrm{a}\end{array}$ \\
\hline $\begin{array}{l}\text { Tibetan } \\
\text { Plateau }\end{array}$ & $\begin{array}{l}\text { Integrated from } 8 \text { series including } \\
\delta^{18} \mathrm{O} \text { in ice cores, juniper tree ring } \\
\text { width, total organic carbon, and } \\
\text { long-chain alkenone. }\end{array}$ & $\begin{array}{l}\text { About } \\
80^{\circ}-102^{\circ} \mathrm{E} \\
25^{\circ}-38^{\circ} \mathrm{N}\end{array}$ & $\begin{array}{l}\text { Annual } \\
\text { mean tem- } \\
\text { perature }\end{array}$ & $\begin{array}{l}\mathrm{AD} \\
1-2000\end{array}$ & $10 \mathrm{yr}$ & $\begin{array}{l}\text { Ge et al., } \\
2013 \mathrm{a}\end{array}$ \\
\hline $\begin{array}{l}\text { Eastern } \\
\text { Tibetan } \\
\text { Plateau }\end{array}$ & $\begin{array}{l}\text { Integrated from } 12 \text { chronologies from } \\
\text { tree ring width. }\end{array}$ & $\begin{array}{l}87^{\circ}-102^{\circ} \mathrm{E} \\
27^{\circ}-38^{\circ} \mathrm{N} \\
3100-4500 \mathrm{~m}\end{array}$ & $\begin{array}{l}\text { Mean tem- } \\
\text { perature } \\
\text { from June } \\
\text { to August }\end{array}$ & $\begin{array}{l}\text { AD } \\
1000-2005\end{array}$ & $1 \mathrm{yr}$ & $\begin{array}{l}\text { Wang et } \\
\text { al., } 2015\end{array}$ \\
\hline
\end{tabular}

\subsection{Method}

Ensemble empirical mode decomposition (EEMD) is used in this study to extract temperature variations on different time scales and to further analyze the phase differences for decadal, multi-decadal, and centennial variations of temperature among the four regions. This method is an optimized plan originated from the empirical mode decomposition (EMD) method induced by Huang et al. (1998) and is able to overcome the edge effect and scale mixing problem by calculating the mean of an ensemble of trials that consists of the original signal and white noises of a finite amplitude (Huang et al., 2007; 2008). EEMD has advantages compared with Fourier or wavelet transforms due to its self-adaptive nature because it is a local decomposition method (Ayenu-Prah and Attoh-Okine, 2009). EEMD has been widely used in multi-scale analysis of temperature in recent years (Wang and Li, 2011; Wei and Qiao, 2016). During the EEMD in this study, the signal-to-noise ratio is set to 0.2, and the sample size is 1000 . It is worth noting that the Eastern Tibetan Plateau series has an annual resolution, while the other four series have decadal resolution. The arithmetic mean for each decade is calculated for the Eastern Tibetan Plateau series before EEMD to make sure that all five series have the same temporal resolution.

\section{Results and discussion}

\subsection{Temperature variation in each region during the MCA and key evidence}

Figure 1a shows the temperature variation in China for the past 2000 years integrated from 
28 proxy reconstructions such as historical documents, tree rings, stalagmites, lake sediments, and ice cores. Despite the existence of several cold decades in the middle and late 12th century, the 10th-13th centuries were the longest warm period on the centennial scale. Taking AD900-1900 as the reference period (REF, herein after), which covered both the MCA and Little Ice Age (LIA), the mean temperature of $950-1250$ was $0.3^{\circ} \mathrm{C}$ higher than in REF and $0.5^{\circ} \mathrm{C}$ higher than in the LIA (about $1450-1850$ ). The warm climate lasted until around 1300. The mean temperature of the two warmest 100 years (1020-1120 and 1190-1290)

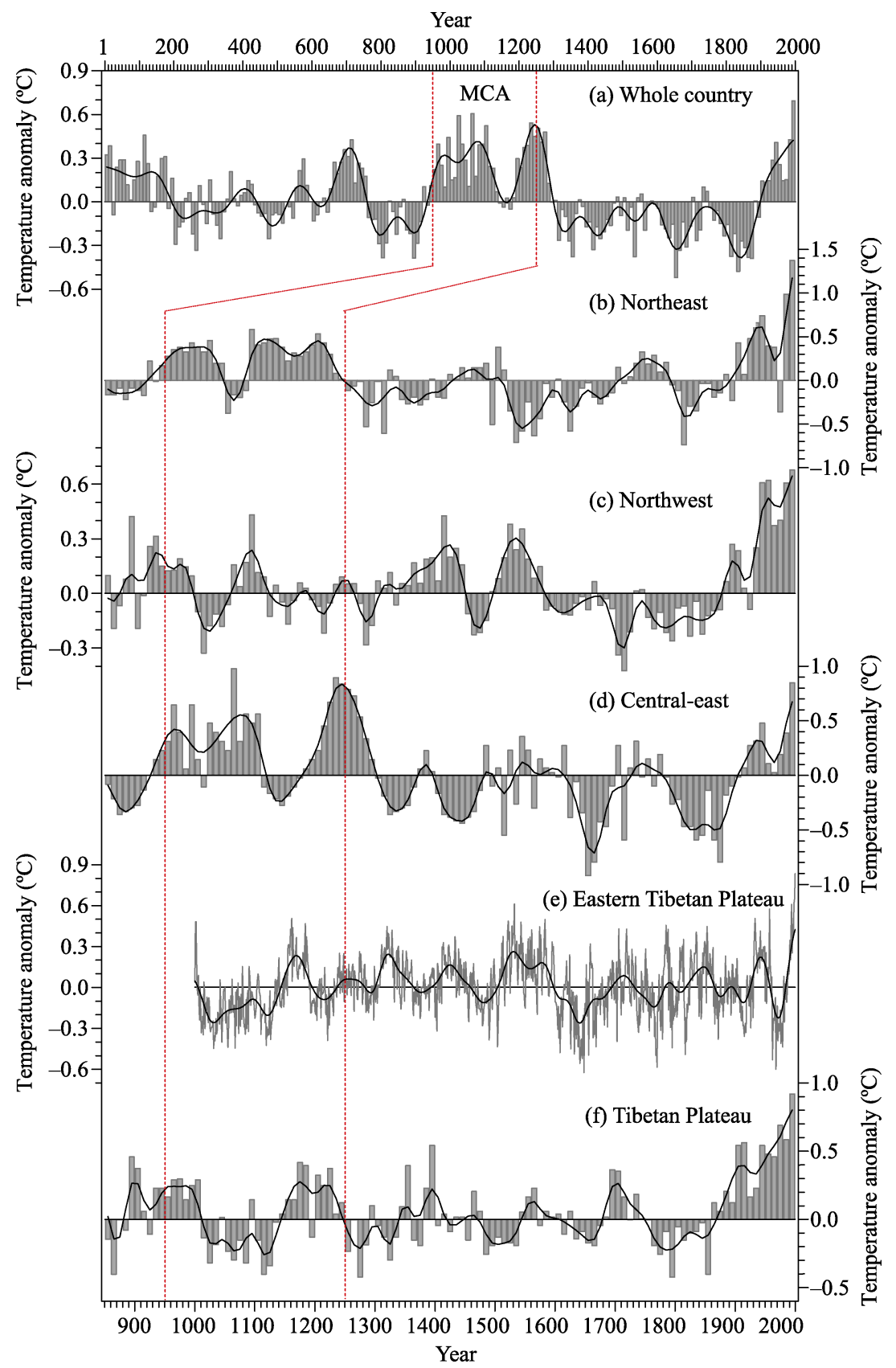

Figure 1 Temperature reconstructions for China (a) and different regions of China (b-f) 
in the MCA was slightly higher than that of the 20th century. Meanwhile, the mean temperature of the two warmest 30 years (1080-1110 and 1230-1260) was comparable to that of the warmest 30 years in the 20th century (1970-2000). However, comparison of five series from different regions shows that there are disagreements in the beginning and ending of this warm period around the 10th-13th centuries. Furthermore, the decadal to multi-decadal variations are also different among regions.

(1) Northeast China

A warm climate in Northeast China existed between 920 and 1250 (Figure 1b), during which the mean temperature for $950-1250$ was $0.3^{\circ} \mathrm{C}$ higher than that of REF. It contained two warm periods lasting more than 100 years (950-1050 and 1090-1190), and three warm peaks lasting 30 years $(1000-1030,1110-1140$, and 1190-1220). However, the mean temperature of both the centennial warm periods and 30-year warm peaks was lower than that of the 20th century. Between these two centennial warm periods, there was a relatively cold period that lasted about 40 years. This was confirmed by the former and later Ambassador-to-Liao Poetry by Su Song, a senior official in the Song Dynasty.

Su Song visited the Liao Dynasty during the winter of 1066 to pick up the Liao envoy and returned to Song in January 1067 (lunar calendar). He then escorted the Liao envoy back, departing from Capital Bianliang (now Kaifeng in Henan Province) on the fifth day of the tenth month in 1068 (Solar calendar is 11/2/1068, the lunar calendar is translated into solar calendar below), and was back in Bianliang in January 1069. The first Ambassador-to-Liao Poetry, which included 30 poems, was written based on the knowledge in those journeys which mostly occurred in winter (Zhao, 1992). Ten years later, Su Song left the capital again on 10/22/1077 to attend the birthday celebration of the emperor of Liao. He returned on 2/13/1078 and wrote the second Ambassador-to-Liao Poetry on his way back (Chen and Qi, 1993). In the first Ambassador-to-Liao Poetry, Su described the extremely cold winters in 1066 and 1068 with, "the north land was covered with ice." However, according to Su's poems from the second Ambassador-to-Liao Poetry (10 years later), when he arrived at Liao's capital on 12/04/1077, he saw that, due to the warm climate, even the Tuhe River was not frozen. The people thought this was lucky and wrote about it in letters to their friends and colleagues. In another poem, he recorded the following: "We left Guangping on the $12 / 27 / 1077$. The weather was unusually warm, and people only needed to wear thin leather jackets." These descriptions show that the region in the northern part of North China to Liaodong was not frozen during the first 10 days of December; this was completely different from the cold winters of ten years ago. According to modern observations, the average starting date of soil freezing in Beijing is November 10, and the latest date is November 27. The average freezing date of Kunming Lake is November 17, and the latest date is December 3 (Wan, 1986). It is worth noting that the latitude of Liao's capital is $1.5^{\circ} \mathrm{N}$ north of Beijing, and it is hundreds of meters higher in altitude; meanwhile, the city of Guangping $\mathrm{Fu}$ is even farther north (Guo et al., 1986). The beginning of winter in these places is supposed to be approximately 15 days earlier than in Beijing. This suggests that the phenophase in 1077 was delayed by at least 15 days compared with the modern average. Although these records can only confirm that there was an unusually warm winter in 1077, we still infer from Su's poems that the officer noticed the climate transition.

(2) Northwest China 
Figure 1c shows that the warm climate in Northwest China started from approximately 920 and lasted until around 1270. It is noteworthy that multi-decadal variations and a cooling trend were found in this period, which made the mean temperature merely comparable to that of the REF. When compared with the 20th century, even the warmest century and warm peaks were significantly colder. In this period, the climate was warmer in 920-1000 and 1060-1120 and colder in 1000-1060 and 1120-1220. Afterward, it turned warmer again in 1220-1270, but this warming was so weak that previous studies thought that there was no significant warm period in Northwest China during 1000-1300 (Wang et al., 2007).

However, temperature reconstructions based on recorded planting boundaries, cropping systems, plant, and abnormal hydro-meteorological phenology showed that temperature in the eastern part of Northwest China around 960 was basically the same as that during 1951-1980. A warming trend continued from the $960 \mathrm{~s}$ to $1010 \mathrm{~s}$, leading to the warm climate in the $1040 \mathrm{~s}-1110 \mathrm{~s}$, which was at least $0.5^{\circ} \mathrm{C}$ warmer than the climate in $1951-1980$. After the $1110 \mathrm{~s}$, the climate in this area turned cold, and the temperature during the $1120 \mathrm{~s}-1180 \mathrm{~s}$ was $0.5^{\circ} \mathrm{C}-1.0^{\circ} \mathrm{C}$ lower than that from 1951 to 1980 . The coldest period occurred around the $1170 \mathrm{~s}$, with a temperature $1.0^{\circ} \mathrm{C}$ lower than that in $1951-1980$. However, the climate became warm again in the late 12th century and lasted until at least the mid-late 13th century. The warmest stage in the MCA was the $1210 \mathrm{~s}-1250 \mathrm{~s}$, which was about $1.0^{\circ} \mathrm{C}$ warmer than the period of 1951-1980. It rapidly became cold after the 1260s and entered a cold stage in the late 13th century (Hao et al., 2009). This suggests that the climate in the eastern part of Northwest China during the MCA was generally warm, and the mean temperature of the MCA should be at least comparable to that of the 20th century. Furthermore, temperatures of those multi-decadal warm peaks were likely higher than those of the later part of the 20th century, especially for $1220-1270$ which was $0.3^{\circ} \mathrm{C}-0.5^{\circ} \mathrm{C}$ warmer. This significantly warm period was not detected in tree ring reconstruction, which might have been because of the joint influence of temperature and precipitation on tree rings, since there was severe drought in Qilian Mountain during that time (Shao et al., 2010; Yang et al., 2014).

(3) Central-east China

Figure 1d shows that the warm climate in Central-east China started from 930 and ceased at approximately 1300 and contained two warm stages lasting more than 100 years and a multi-decadal cold stage. The mean temperature of $950-1250$ was about $0.3^{\circ} \mathrm{C}$ higher than that of the REF; meanwhile, the first warm stage $(930-1110)$ was about $0.4^{\circ} \mathrm{C}$ warmer than the REF. However, there was obvious decadal to multi-decadal variation in this sub-period of 930-1110: it had two warm peaks and one cold valley. The first warm peak was in 950-980, during which the mean temperature was $0.5^{\circ} \mathrm{C}$ higher than that in the REF. The cold valley occurred in 1000-1050, and the coldest decade was the $1010 \mathrm{~s}$, with a $0.1^{\circ} \mathrm{C}$ cooling. This coldest decade happened to occur at the beginning of the Oort Minimum period (1010-1050) in solar activity reconstruction. Even though the next decade (the 1020s) was relatively warm, the temperature in the following decades (from the 1020 s to 1050 s) dropped continuously. This corresponds well with the Oort Minimum. After this drop, the climate became warmer again, and the temperature during $1060-1090$ reached $0.6^{\circ} \mathrm{C}$ higher than the REF. The warmest decade in 1060-1090 was the 1060 s, which was warmer than the $\mathrm{REF}$ for up to $1.0^{\circ} \mathrm{C}$.

The period of $1110-1190$ was a cold stage in Central-east China and was $0.1^{\circ} \mathrm{C}$ cooler 
than the REF. The coldest valley occurred around $1130-1160$, with a $0.2^{\circ} \mathrm{C}$ cooling. It can be seen from the historical records that there was a significant increase in the number of extreme cold events, such as heavy snow and freezing hazards, and subtropical fruit trees suffered from cold injuries. For example, it was recorded that in the year of 1110 the winter in Lake Taihu basin was so cold that the citrus in Dongting mountain was killed by frost ${ }^{1}$, and the same disaster hurt lychee trees in Fujian Province (Ge, 2011). Similar freezing hazards were also found in 1113, 1126, 1132, and 1135 (Man, 2009). Nevertheless, there is no record of northward shift of fruit planting in subtropical areas. On the contrary, it was recorded that the lychee in Fujian Province "sprouted in the next spring, and flourished after several years," and citrus planting in Dongting mountain was never stopped throughout the entire 12th century (Man, 1999). This is quite different compared to the LIA, during which frequent cold injuries usually led to remarkable southward shift of subtropical fruit planting. This finding indicates that in spite of more frequent freezing injuries during 1110-1190, there was no remarkable change in climate zones. Based on statistics of the six severe winters recorded during 1110-1140, it is suggested that the frequency of severe winters was once every five years; this indicates that there was an $80 \%$ assurance rate for the subtropical fruit trees. A similar frequency also occurred in Central-east China during 1951-1980 (Zheng et al., 2012). This is still acceptable for fruit planting based on agroclimatic resources researches, which makes it reasonable that subtropical fruit planting did not move southward. This cold stage lasted until the end of the 12th century according to a variety of historical records, because records on severe winters were still found in 1185 and 1190 but rarely happened since then. The mid-12th century might have been the coldest period since there were more frequent river icing records in the Lake Taihu basin (Man, 2009).

The second warm sub-period for Central-east China during the MCA was in 1190-1300, during which the region was $0.5^{\circ} \mathrm{C}$ warmer than in the REF, and the period of $1230-1260$ was the warmest 30 years, with a $0.8^{\circ} \mathrm{C}$ warmer temperature compared to REF. There was a remarkable northward shift for the north boundaries of subtropics and warm temperate zones, and the movement could be at least $1^{\circ} \mathrm{N}$, as indicated by historical documents (Zhang, 1993; Man, 1999; 2009; Zheng et al., 2012). This corresponds well with the upward trend of the tree line in Ural Mountain (about $60^{\circ} \mathrm{N}$ ) during the late 12th century and the 13th century (Shiyatov, 1993; Bradley, 2000; Shiyatov and Mazepa, 2015). It can be concluded that the warm climate during this period was common for many regions in the Northern Hemisphere.

(4) Tibetan Plateau

Figure 1f shows that the warm period for the Tibetan Plateau corresponding to the MCA appeared in 890-1250, which is earlier than for the other regions in China. Its multi-decadal to centennial variation is also larger than those of the other regions. However, due to the relatively low variance explained by most of the proxy data, the amplitude for reconstructed

\footnotetext{
1 This was originally recorded on the Notes by Yanbei by Lu Youren, a calligrapher and bibliophile in the Yuan Dynasty, and then quoted by many local chronicles such as Chronicles in Taihu. The following was recorded: "There are people planting citrus for a living in Dongting mountain. In the first year of the Zhenghe Era in Song Dynasty, the winter was so cold that the rivers were totally frozen and the citrus were all dead." Based on the original text, the extremely cold winter was in the first year of the Zhenghe Era, which is 1111 . However, this was the only cold record among all documents. On the contrary, plenty of extremely cold events during the winter of 1110 were recorded by many documents, including the frozen lychees incident mentioned in this article. Therefore, it was speculated that this incident might also have happened in 1110 (Man, 2009).
} 
temperature variation might be so low that the mean temperature for this period only reached $0.1{ }^{\circ} \mathrm{C}$ higher than the REF. There were also two warm sub-periods (890-1010 and 1140-1250) and one cold sub-period (1010-1140) on the centennial scale. The warmest centuries for those two warm sub-periods were 890-990 and 1150-1250, respectively, both of which were warmer than the REF by about $0.2^{\circ} \mathrm{C}$. The warmest 30 years for each sub-period were $890-920$ and $1160-1190$ and were $0.3^{\circ} \mathrm{C}$ warmer than the REF but colder than the 20th century. The cold valley was around the $1110 \mathrm{~s}$, and the temperature for the coldest decade was $0.5^{\circ} \mathrm{C}$ lower than that of the 20th century. It is noteworthy that the first 40 years of this sub-period happened to correspond with the sunspot activity of the Oort Minimum period, when the glacier advanced in Hailuogou Valley. This cold sub-period could also be proved by the tree rings-based temperature reconstruction for the past 1000 years in the Eastern Tibetan Plateau, as shown in Figure 1e (Wang et al., 2015). The cold climate in the Tibetan Plateau during the MCA seems to be longer and greater than in other regions in China (compare Figure 1f with Figures $1 \mathrm{~b}-\mathrm{d}$ ). This may be related to the high altitude and sensitivity to climate change in this region.

Many studies, especially reconstructions based on $\delta^{18} \mathrm{O}$ in ice cores, suggest that temperature in the Tibetan Plateau for the past 2000 years showed decadal to multi-decadal fluctuation in the first 1800 years and then increased rapidly in the recent 200 years (Thompson et al., 2006; Chen et al., 2015). Therefore, there might not be long and lasting warm or cold periods during MCA and LIA in the Tibetan Plateau as in other regions of the Northern Hemisphere. However, the temperature reconstructed from multiple climatic proxy records with envelopment analysis showed that, even though the two centennial warm sub-periods (890-1010 and 1140-1250) and their warm peaks were relatively colder than the 20th century, there did exist a warm period of MCA in the Tibetan Plateau. It just started a little bit earlier compared with the MCA in other regions in China, and the cold sub-period (1010-1140) between two warm sub-periods lasted longer.

\subsection{The phase differences of temperature variation between different regions in China during the MCA}

Figure 2 shows the EEMD results of reconstructed temperature series for different regions in China, and the variances explained by the intrinsic mode functions (IMFs) are given in Table 2. The first intrinsic mode function (IMF 1) shows the temperature variation characteristics at a period of quasi-30 years. During the MCA, regional temperature variations were basically synchronous in 950-1130, yet their amplitudes became smaller and the phase differences appeared in 1130-1250.

The second and third intrinsic mode functions (IMF 2 and 3) mainly indicate the characteristics of quasi-centennial variation on temperature in different regions. The increase in temperature in the early 10th century can be found in each region. Moreover, there are two cold sub-periods under the relatively warm background during the MCA for each region. As for the phase difference between the regions, it can be found that the centennial variation for Northwest China is basically the same as that for Central-east China during the MCA. Compared with Northwest and Central-east regions, the beginning of two cold sub-periods for Northeast China is postponed by about 30-40 years, and the end of the warm climate advanced by $40-50$ years. For the Tibetan Plateau, the transition into the first cold 


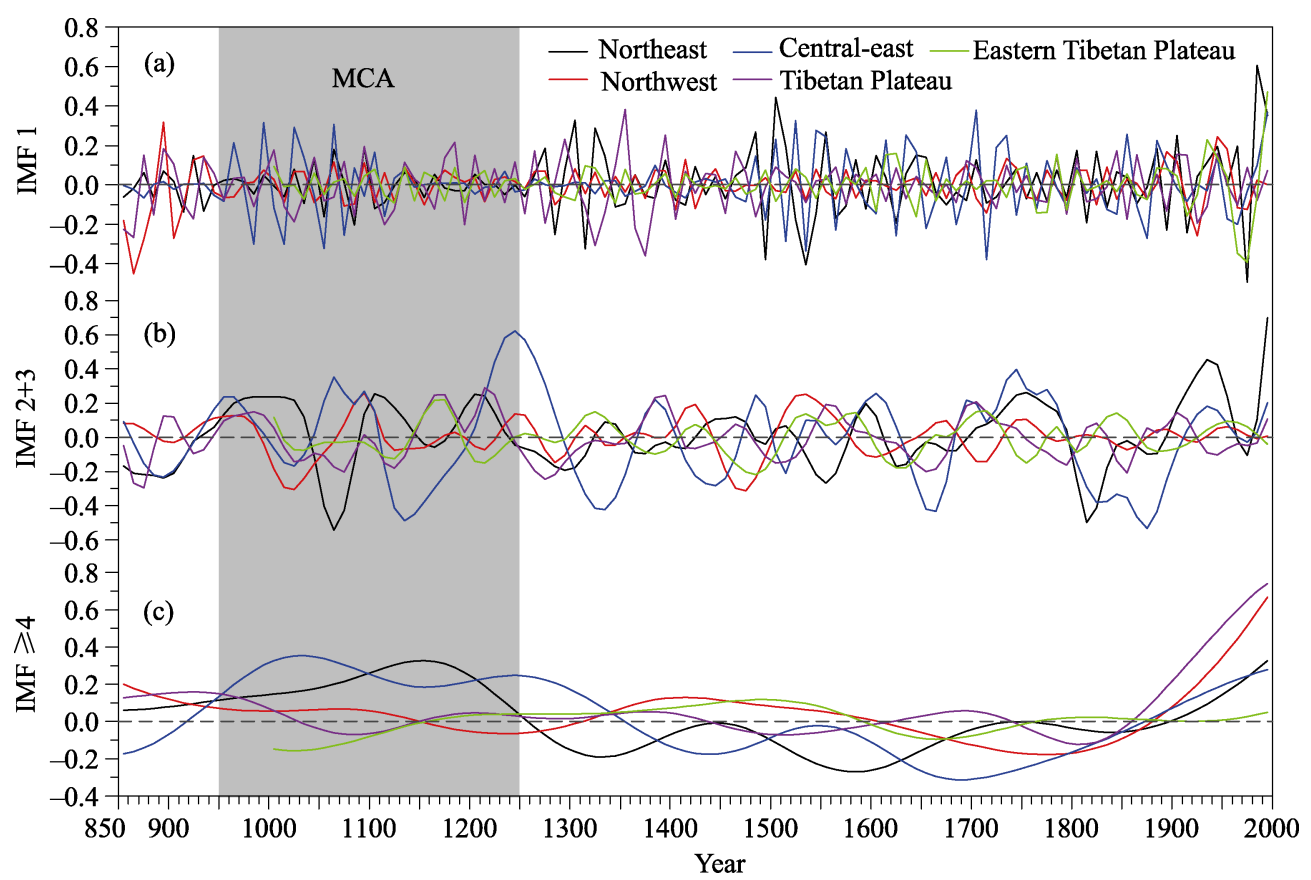

Figure 2 EEMD analysis of reconstructed temperature series for different regions in China

sub-period is in synchronous with that of Northwest China and Central-east China; these transitions all occurred in the early 11 th century. However, the cold sub-period in the Tibetan Plateau lasts longer than in other regions, and the region does not become warm until the mid-12th century. This leads to a large phase difference in centennial variation from the mid-11th to 13th century between Tibetan Plateau and other regions. The end of the warm climate for the Tibetan Plateau, however, is consistent with that for Northeast China, which is 40 to 50 years earlier than that for the Northwest China and Central-east China.

The sum of the fourth and subsequent intrinsic mode functions (IMF $\geq 4$ ) and the residual indicates the temperature variation on the millennial scale for each region. It is noteworthy that a difference could be found between the MCA and LIA for Northeast China and Central-east China, yet there is no difference for Northwest China and the Tibetan Plateau. In general, the warmth in the MCA is comparable to that in the 20th century for Central-east China, is slightly weaker than in the 20th century for Northeast China and is significantly weaker than in the 20th century for Northwest China and the Tibetan Plateau. These results are consistent with previous studies, which suggested that there exists a prominent warm MCA for Eastern China but no significant warm period during 1000-1300 for Western China (Wang et al., 2007).

However, it should be noted that the possible causes for the aforementioned differences

Table 2 Explained variance by IMFs combination for regional reconstructions

\begin{tabular}{cccccc}
\hline IMF & Northeast China & Northwest China & Central-east China & Tibetan Plateau & Eastern Tibetan Plateau \\
\hline IMF 1 & $29.5 \%$ & $24.5 \%$ & $11.3 \%$ & $31.5 \%$ & $42.7 \%$ \\
IMF 2+3 & $29.1 \%$ & $28.6 \%$ & $40.7 \%$ & $25.9 \%$ & $38.0 \%$ \\
IMF $\geq 4$ & $21.9 \%$ & $46.7 \%$ & $29.7 \%$ & $34.3 \%$ & $18.7 \%$ \\
\hline
\end{tabular}


might be not only the regional difference in temperature variation but also the different sensitivities of various proxy records in response to temperature variation with different time scales. Table 2 shows that the variance explanation of IMF1 in Central-east China is only $11.3 \%$, which is much lower than that of the other regions. The possible reason for this could be that the documentary records used in temperature reconstruction for this region, especially for the temperature before 1500 , are mainly from phenological evidence indicating climate zones' movement. This kind of evidence has been suggested to be insensitive to decadal temperature variation, and 30 years is the most suitable time scale in temperature reconstruction using such evidence (Ge et al., 2008). Furthermore, the unobvious difference in temperature between the MCA and LIA for Northwest China and the Tibetan Plateau might have resulted from the main proxy record in their temperature reconstruction since tree rings retains less low-frequency signals. Taking the decadal to multi-decadal temperature variation for Northwest China as an example, the amplitude of temperature variation reconstructed by historical documents is larger than $1.5^{\circ} \mathrm{C}$ but is lower than $0.7^{\circ} \mathrm{C}$ in reconstructions using tree rings. A similar situation might also be found in reconstruction for Northeast China, which suggests that the amplitude of temperature variation reconstructed from $\delta^{18} \mathrm{O}$ in peat might be much smaller than that reconstructed from other proxies; however, the specific range of their disparity is hard to estimate due to lack of evidence. Besides, there might be disagreement in dating precision between different proxy records. For example, the dating of historical records and tree rings could be accurate, but there is uncertainty in the dating of ice cores, $\delta^{18} \mathrm{O}$ in peat, and lake sediment. For $\delta^{18} \mathrm{O}$ in peat and lake sediment, the dating errors could be up to decades or over 100 years. Nevertheless, the decadal to multi-decadal temperature variation revealed by the regional temperature series reconstructed from ice cores, $\delta^{18} \mathrm{O}$ in peat, and lake sediment is basically the same as that recorded in historical documents. This suggests that the influences induced by different proxy data are unobvious after integration. Therefore, further exploring the sensitivity of different proxy data to temperature variation on different timescales is crucial for improving the accuracy of regional climate reconstruction using multi-proxy data. This should be considered in future studies.

\section{Conclusion}

This study investigates five regional temperature series for four regions of China (i.e., Northeast, Northwest, Central-east, and Tibetan Plateau) synthesized from recently published multi-proxy data in different locations along with temperature records from Chinese historical documents, and analyzes the decadal to centennial variations of temperature for China during the MCA and its regional differences. The EEMD method is used to analyze the phase differences between decadal, multi-decadal, and centennial variations of temperature among the regions.

The results show that the 10th-13th centuries are the longest warm period over the past 2000 years on the centennial scale over China. The mean temperature of $950-1250$ was about $0.3^{\circ} \mathrm{C}$ higher than that of $900-1900$ and $0.5^{\circ} \mathrm{C}$ higher than that of $1450-1850$ (i.e., LIA). This warm period lasted until around 1300. The two warmest centuries occurred in 1020-1120 and 1190-1290 and were slightly warmer than the 20th century. The two warmest 30 years were $1080-1110$ and $1230-1260$, and the temperatures were comparable to those in 1970-2000, i.e., the warmest 30 years of the 20 th century. 
However, there was regional disparity in the beginning and ending decades of the MCA and in the amplitudes and phases of temperature variations on decadal to centennial scales. On the inter-decadal scale, regional temperature variations were similar during 950-1130, but amplitudes became smaller and phases became inconsistent during 1130-1250. On the quasi-centennial scale, all four regions warmed in the early 10th century and experienced two cold intervals during the MCA. However, despite the synchronized centennial variation of temperature in Northwest and Central-east China, there were significant phase differences between Northeast China and the Tibetan Plateau, and the warm climate in these two regions ended about 40-50 years earlier than in the other two regions. On the multi-centennial scale, noteworthy differences could be found between the MCA and LIA for Northeast and Central-east China, yet there was little difference for Northwest China and the Tibetan Plateau. In general, the warmth in the MCA was comparable to that in the 20th century for Central-east China, slightly weaker for Northeast China, and significantly weaker for Northwest China and the Tibetan Plateau. Possible causes for these differences might be not only the regional disparity in temperature variations but also the different sensitivity of various proxy records in response to temperature variation with different time scales.

\section{References}

Ayenu-Prah A Y, Attoh-Okine N O, 2009. Comparative study of Hilbert-Huang transform, Fourier transform and wavelet transform in pavement profile analysis. Vehicle System Dynamics, 47(4): 437-456.

Bradley R S, 1993. High Resolution Records of Past Climate from Monsoon Asia: The Last 2000 years and Beyond: Recommendations for Research. Bern, Switzerland: IGBP PAGES Workshop Report Series 93-1.

Bradley R S, 2000. Past global changes and their significance for the future. Quaternary Science Reviews, 19: $391-402$.

Bradley R S, Hughes M K, Diaz H F, 2003. Climate in medieval time. Science, 302: 404-405.

Chen Deliang, $\mathrm{Xu}$ Baiqing, Yao Tandong et al., 2015. Assessment of past, present and future environmental changes on the Tibetan Plateau. China Science Bulletin, 60: 3025-3035. (in Chinese)

Chen Zibin, Qi Jingzhi, 1993. Annotation of Su Song's Ambassador-to-Liao Poetry, a friendly journey of thousands kilometers. Journal of Chengde Teachers College for Nationalities, 2: 1-38. (in Chinese)

Crowley T J, Lowery T S, 2000. How warm was the medieval warm period? AMBIO: A Journal of the Human Environment, 29(1): 51-54.

Diaz H F, Trigo R, Hughes M K et al., 2011. Spatial and temporal characteristics of climate in medieval times revisited. Bulletin of the American Meteorological Society, 92(11): 1487-1500.

Ge Quansheng, 2011. Climate Change in Chinese Dynasties. Beijing, China: Science Press. (in Chinese)

Ge Quansheng, Hao Zhixin, Zheng Jingyun et al., 2013a. Temperature changes over the past $2000 \mathrm{yr}$ in China and comparison with the Northern Hemisphere. Climate of the Past, 9(3): 1153-1160.

Ge Quansheng, Hua Zhong, Zheng Jingyun et al., 2015. Forcing and impacts of warm periods in the past 2000 years. Chinese Science Bulletin, 60(18): 1727-1734. (in Chinese)

Ge Quansheng, Liu Haolong, Ma Xiang et al., 2017. Characteristics of temperature change in China over the last 2000 years and spatial patterns of dryness/wetness during cold and warm periods. Advances in Atmospheric Sciences, 34(8): 941-951.

Ge Quansheng, Liu Jian, Fang Xiuqi et al., 2013b. General characteristics of temperature change and centennial warm periods during the past 2000 years. Acta Geographica Sinica, 68(5): 579-592. (in Chinese)

Ge Quansheng, Zheng Jingyun, Hao Zhixin et al., 2014. State-of-the-arts in the study of climate changes over China for the past 2000 years. Acta Geographica Sinica, 69(9): 1248-1258. (in Chinese)

Ge Quansheng, Zheng Jingyun, Hao Zhixin et al., 2016. Recent advances on reconstruction of climate and extreme events in China for the past 2000 years. Journal of Geographical Sciences, 26(7): 827-854.

Ge Quansheng, Zheng Jingyun, Tian Yanyu et al., 2008. Coherence of climatic reconstruction from historical documents in China by different studies. International Journal of Climatology, 28(8): 1007-1024. 
Guo Hao, Li Peng, Tai Xinhe, 2012. Research of Liao River. History and Geography of Northeast China, 6: 35-39. (in Chinese)

Hao Zhixin, Ge Quansheng, Zheng Jingyun, 2009. Temperature variations during the Song and Yuan dynasties (960-1368 A.D.) in the eastern part of Northwest China. Quaternary Sciences, 29(5): 871-879. (in Chinese)

Huang N E, Shen Zheng, Long S R et al., 1998. The empirical mode decomposition and the Hilbert spectrum for nonlinear and non-stationary time series analysis. Proceedings of the Royal Society of London A: Mathematical, Physical and Engineering Sciences, 454(1971): 903-995.

Huang N E, Wu Zhaohua, 2008. A review on Hilbert-Huang transform: Method and its applications to geophysical studies. Reviews of Geophysics, 46(2): RG2006.

Hughes M K, Diaz H F, 1994. Was there a 'medieval warm period', and if so, where and when? Climatic Change, 26: $109-142$.

IPCC, 2012. Managing the Risks of Extreme Events and Disasters to Advance Climate Change Adaptation. A Special Report of Working Groups I and II of the Intergovernmental Panel on Climate Change. Cambridge, UK, and New York, NY, USA: Cambridge University Press.

IPCC, 2014. Summary for policymakers. In: Climate Change 2014: Impacts, Adaptation, and Vulnerability. Part A: Global and Sectoral Aspects. Contribution of Working Group II to the Fifth Assessment Report of the Intergovernmental Panel on Climate Change. Cambridge, UK and New York, NY, USA: Cambridge University Press.

Man Zhimin, 1999. Relationship between geographic northern bounds of orange cultivation in Chinese history and the climatic changes. Fudan Journal (Social Sciences), 5: 72-77. (in Chinese)

Man Zhimin, 2009. Climate Change Research in Chinese History. Jinan: Shandong Education Press. (in Chinese)

PAGES, 2009. Science Plan and Implementation Strategy. IGBP Report No.57. Stockholm: IGBP Secretariat.

PAGES, 2014. PAGES Restructured. Past Global Changes Magazine, 22(1): 3.

Qin Dahe, 2014. Climate change science and sustainable development. Progress in Geography, 33(7): 874-883. (in Chinese)

Shao Xuemei, Xu Yan, Yin Zhiyong et al., 2010. Climatic implications of a 3585-year tree-ring width chronology from the northeastern Qinghai-Tibetan Plateau. Quaternary Science Reviews, 29(17): 2111-2122.

Shiyatov S G, 1993. The upper timberline dynamics during the last 1100 years in the Polar-Ural mountains. In: Oscillations of the Alpine and Polar Tree Limits in the Holocene. Stuttgart: Gustav Fischer Verlag.

Shiyatov S G, Mazepa V S, 2015. Contemporary Expansion of Siberian Larch into the Mountain Tundra of the Polar Urals. Russian Journal of Ecology, 46(6): 495-502.

Steffen W, 2003. Preface of Chinese Edition. In: Global Change and the Earth System: A Planet Under Pressure. Chen Panqin, Lin Hai, Ge Quansheng et al. trans. Beijing: IGBP. (in Chinese)

Thompson L G, Mosley-Thompson E, Brecher H et al., 2006. Abrupt tropical climate change: Past and present. Proceedings of the National Academy of Sciences, 103(28): 10536-10543.

Wan Minwei, 1986. Selected Natural Calendars of China. Beijing: Science Press. (in Chinese)

Wang Bing, Li Xiaodong, 2011. Multi-scale fluctuation of European temperature revealed by EEMD Analysis. Acta Scientiarum Naturalium Universitatis Pekinensis, 47(4): 627-635. (in Chinese)

Wang Jianglin, Yang Bao, Ljungqvist F C, 2015. A millennial summer temperature reconstruction for the eastern Tibetan Plateau from tree-ring width. Journal of Climate, 28(13): 5289-5304.

Wang Shaowu, Wen Xinyu, Luo Yong et al., 2007. Reconstruction of temperature series of China for the last 1000 years. Chinese Science Bulletin, 52(8): 958-964. (in Chinese)

Wei Meng, Qiao Fangli, 2016. Attribution analysis for the failure of CMIP5 climate models to simulate the recent global warming hiatus. Science China Earth Sciences, 46(12): 1675-1688. (in Chinese)

Wu Zhaohua, Huang N E, Long S R et al., 2007. On the trend, detrending, and variability of nonlinear and nonstationary time series. Proceedings of the National Academy of Sciences, 104(38): 14889-14894.

Yang Bao, Qin Chun, Wang Jianglin et al., 2014. A 3,500-year tree-ring record of annual precipitation on the northeastern Tibetan Plateau. Proceedings of the National Academy of Sciences, 111(8): 2903-2908.

Zhang De'er, 1993. A study on the medieval warm period in China. Quaternary Sciences, 13(1): 7-15. (in Chinese)

Zhao Ke, 1992. Research for the time that Su Song picked up Liao envoy and his first visit to Liao, a correction for chronology of Su Song. The Northern Forum, 4: 58-59. (in Chinese)

Zheng Jingyun, Ding Lingling, Hao Zhixin et al., 2012. Extreme cold winter events in southern China during AD 1650-2000. Boreas, 41: 1-12. 